\title{
Influence of the addition of PEG into PCL-based waterborne polyurethane-urea dispersions and films properties
}

\author{
Julen Vadillo, ${ }^{1,2}$ Izaskun Larraza, ${ }^{1}$ Aitor Arbelaiz, ${ }^{1}$ Maria Angeles Corcuera, ${ }^{1}$ Maud Save, ${ }^{2}$ \\ Christophe Derail, ${ }^{2}$ Arantxa Eceiza $\mathbb{1}^{1}$ \\ 1"Materials + Technologies" Research Group (GMT), Department of Chemical and Environmental Engineering, Faculty of Engineering \\ of Gipuzkoa, University of Basque Country, Plz. Europa 1, Donostia-San Sebastian 20018, Spain \\ ${ }^{2}$ CNRS/UNIV Pau and Pays Adour/ E2S-UPPA, Institut des Sciences Analytiques et de Physico - Chimie pour I' Environnement et les \\ Materiaux UMR5254, Pau 64000, France \\ Correspondence to: C. Derail (E-mail: christophe.derail@univ-pau.fr) and A. Eceiza (E-mail: arantxa.eceiza@ehu.es)
}

ABSTRACT: In this work, segmented waterborne polyurethane-urea (WBPUU) dispersions containing hydrophobic polycaprolactone (PCL) and hydrophilic poly(ethylene glycol) (PEG) in different molar ratios are synthesized and used for the subsequent preparation of films by casting. The molar ratio of PEG is gradually increased up to 0.20 in order to analyze the effect of low hydrophilic PEG content (from 1.7 to $7.1 \mathrm{wt} \%$ ) on the properties of resulting dispersions and films. Regarding the dispersions, the addition of PEG results in an increase of the particle size, from $86 \pm 1$ in the case of pure PCL-based system to $112 \pm 15$ for systems containing 7.1 wt \% of PEG, as well as in the formation of a core-shell structure in the particles. Films show different behaviors depending on their PEG content. WBPUUs containing just PCL or very low content of PEG in the soft segment present higher stiffness. However, the addition of PEG in a content of $3.4 \mathrm{wt} \%$ or higher hinder the ability of the short-range ordering of the hard segment, increasing the elongation at break from $842 \pm 102 \mathrm{MPa}$ for PCL-based WBPUU to $1312 \pm 84 \mathrm{MPa}$ for the system with the highest PEG content. Systems with higher PEG content form nanoparticles with more segregated core-shell structures inducing to the film a higher hydrophilicity. Hence, the addition of PEG to a PCL-based WBPUU allows to tune the properties of the resulting film increasing the range of application of these materials. @ 2019 Wiley Periodicals, Inc. J. Appl. Polym. Sci. 2020, 137, 48847.

KEYWORDS: emulsion polymerization; morphology; polyurethane; synthesis and processing techniques

Received 5 September 2019; accepted 7 December 2019

DOI: $10.1002 / a p p .48847$

\section{INTRODUCTION}

Thermoplastic-segmented polyurethanes and polyurethane-ureas (PU and PUUs) are part of a wide family of polymeric materials. Their thermal, thermomechanical, and specific mechanical properties as well as their biocompatibility ${ }^{1,2}$ make them remarkably attractive materials for their use in different application fields such as automotive industry, biomaterials, and coatings. ${ }^{3}$ These materials are formed by a soft segment (SS) and a hard one (HS) constituted by a long chain diol, and by both an isocyanate and a chain extender, respectively. In the case of PU, the chain extender is a low=molecular-weight diol, whereas in the case of PUU is a low-molecular-weight diamine. The variation of the nature of the reagents as well as the ratio between HS and SS, which usually are thermodynamically immiscible resulting in a microphase-separated morphology, leads to materials with tunable final properties. ${ }^{4,5}$
One of the major drawbacks of PU and PUU is that due to their hydrophobic nature, their manipulation in liquid phase implies the use of organic solvents. The recent awareness on the environmental issues as well as the increasingly stricter environmental legislation, which limited atmospheric emissions of volatile organic compounds (VOCs), have drawn the interest of many researchers in finding more environmental friendly alternatives for the manipulation of polymeric systems. ${ }^{6}$ One of these alternatives comes from aqueous polymeric systems, like PU and PUU dispersions in water (WBPU and WBPUU), which have experienced increasing attention in the last years since their manipulation does not involve VOC emissions. Additionally, water is a cheap, nontoxic, environmentally benign solvent and it is relatively easy to manipulate, so WBPU and WBPUU have become excellent candidates to substitute classic PU and PUU, respectively, in many applications. ${ }^{7,8}$ 
Inherently, PU and PUU are no miscible in water, but in case of WBPU and WBPUU, ionic groups and hydrophilic nonionic chains contained in the polymer backbone could act as internal emulsifiers enabling the dispersion in water. ${ }^{9}$ Ionic groups, completely or partially neutralized by the presence of counterions, can be cationic-like quaternary ammonium groups and anionic-like carboxylated or sulfonated groups, whereas nonionic can be hydrophilic polymer chains as, for example, poly(ethylene glycol) (PEG), behaving usually as part of the SS. ${ }^{10,11}$ Hence, by using these ionic groups or nonionic highly hydrophilic polyols as emulsifiers, stable waterborne dispersions constituted by PU or PUU nanoparticles can be obtained. When the dispersion is formed, the ionic groups of the particles, surrounded by the counterions forming the electrical double layer, as well as the nonionic hydrophilic domains are arranged in the surface forming the shell of the particle. ${ }^{12,13}$ Conversely, hydrophobic domains will be situated in the center of particles forming the core-shell of the particles. ${ }^{14}$

Attending to the HS, apart from the aforementioned emulsifier, it is composed by a diisocyanate and a short-chained diol or diamine. In the case of diisocyanates, aliphatic isophorone diisocyanate (IPDI) is the most commonly used in the synthesis of waterborne dispersions due to its lower reactivity with water compared to aromatic ones, which allows a better control of the synthesis procedure. ${ }^{15}$ Additionally, its asymmetric structure leads to less ordered structures and thus, eases the diffusion of water during the dispersion step. ${ }^{16}$ Chain extender wise, the most used ones are 1,4 butanediol (1,4-BD) in the case of WBPU and ethylene diamine (EDA) in WBPUU. ${ }^{17}$

Regarding the SS, in the literature, different types of polyols have been reported in the WBPU and WBPUU synthesis; concretely, most of the authors reported systems containing polyester type polycaprolactone (PCL) ${ }^{18-21}$ or polyether type polytetramethylene ether glycol $^{8,22}$; but there are also many works involving other types of polyols as, for example, castor oil, ${ }^{23,24}$ polyisobutyl lactate diol, ${ }^{25}$ polycarbonate of 1,6 -hexanediol, ${ }^{26}$ or even polyols synthesized from $\mathrm{CO}_{2} \cdot{ }^{27}$ Aside from these polyols, which are hydrophobic, other authors reported the use of hydrophilic polyols in WBPUU synthesis, mainly, in order to obtain hydrogels $^{28}$ or as explained before to use them as a nonionic emulsifier. It has been observed that dispersions containing PEG, also known as poly(ethylene oxide) (PEO), with high percentage of solid content (above $30 \mathrm{wt} \%$ ) tends to form physical gels. Yoo et al. synthesized hydrogels based on a 40 wt \% solid content WBPUU dispersion with an SS composed by PEG for wound healing dressings, ${ }^{29}$ whereas Young-Kim et al. prepared a coating coming from a PEG-based WBPUU dispersion with low solid content for waterproof breathable fabrics. ${ }^{30}$

Block copolymers containing PEG hydrophilic block as SS have been also investigated. Yen et al. synthesized a series of WBPUU using poly( $\varepsilon$-caprolactone- $b$-ethylene glycol- $b$ - $\varepsilon$-caprolactone) as polyol. The molecular weight of PEG in the SS and SS content were varied. ${ }^{31}$ In a recent work developed in our group poly(ethylene glycol-b-propylene glycol- $b$-ethylene glycol) and poly(propylene glycol- $b$-ethylene glycol- $b$-propylene glycol) triblock copolymers with PEG blocks with different molecular weights and different PEG contents were also investigated as SS of WBPUU and compared with only PEG-based WBPUU (DíezGarcía et al.). The presence of triblock copolymers as SS resulted into a decrease of Young modulus and elongation at break compared with PEG-based WBPUU. Additionally, it was observed that the use of hydrophobic-hydrophilic triblock copolymer promotes the microphase separation. ${ }^{32}$ In the last years, there has been an increasing interest in using more than one polyol, in order to modify the properties of the final material as well as to incorporate new functionalities. Fuensanta et al. combined two hydrophobic polyols and studied the properties of films prepared from WBPUU synthesized varying the ratio of polycarbonate of 1,6-hexanediol/polyadipate of $\mathrm{BD}$ in the SS. ${ }^{33}$ However, the combination that probably has drawn more attention is the one formed by hydrophilic and hydrophobic polyols. The possibility of producing hydrogels containing a hydrophobic polyol such as PCL has been an interesting field of investigation, concretely for biomedical applications. Tsai et al. prepared hydrogel from a WBPUU, and studied different ratios of PCL with two different copolymers: poly(L-lactide-co-PEO) (PLLA-PEO) and poly(Dlactide-co-PEO) (PDLA-PEO) for its use as a new cell printing material. ${ }^{34}$ Hsu et al. used a combination of PCL and PLLA-PEG copolymer to prepare a WBPUU with thermoresponsive gelation. ${ }^{35}$

The aforementioned literature has proved the versatility of synthesizing WBPUUs by using combinations of polyols for many applications; but in case of hydrophilic/hydrophobic diol combinations, most of the works are focused on the properties of gels instead of films. Regarding the latter, in a previous work developed in our research group, different ratios of a hydrophobic biobased polyol poly(trimethylene ether glycol) (P3MG) and PEG (both $M_{w}=1000 \mathrm{~g} \mathrm{~mol}^{-1}$ ) were used in order to prepare solvent and catalyst free WBPUUs; varying the PEG molar ratio from 0.1 to 0.4 (Díez-García et al.). It was seen that the decrease of the P3MG content result into an increase of both Young modulus and elongation at break, as well as a higher phase separation in the nanoscale. ${ }^{13}$ However, based on our knowledge, there is only a few research works where mixtures of PCL and hydrophilic diols were been used to synthesize WBPU, and there is not research works on using PCL and PEG as SS in the synthesis of WBPUU. Cacik et al. analyzed the influence of the molecular weight of PEG over thermal properties and crystallinity of PCL/PEG-based WBPU. ${ }^{36}$ Hao et al. in contrast studied the behavior in a WBPU varying the PEG content from 0.17 to 0.45 of molar ratio. ${ }^{37}$

Therefore, this work focuses on studying the influence of the variation in the ratio of a hydrophobic diol-like PCL and a hydrophilic diol-like PEG into the properties of dispersions of WBPUU and films prepared from the synthesized dispersions by doing a comprehensive analysis of the influence of low PEG content (from 0.05 to $0.20 \mathrm{M}$ ratio). It is expected that the addition of PEG will increase the hydrophilicity of the film, ${ }^{30}$ as well as modify its morphology and thus its mechanical and thermal properties due to the different natures of PEG compared to the more hydrophobic PCL. However, it is important to determine at which PEG content the effect into the properties of the systems are modified, or in other words, what is the minimal content of 
PEG to achieve this modification of the properties. In this way, the aim of this work was to determine the minimum PEG content in the synthesized WBPUU dispersion at which the properties of the final material change significantly, in order to demonstrate that the incorporation of different contents of PEG could be a suitable strategy to modulate the final properties of the dispersions and films. The synthesized dispersions could be employed in VOCs free coatings or adhesives, as well as base for the preparation of environmentally friendly functional coatings by means of the incorporation of water dispersible nonentities and additives. ${ }^{38-40}$ As explained before, the solid content of the dispersion is a key parameter in order to obtain either dispersions or gels, hence in this work the solid content was maintained low enough ( $25 \mathrm{wt} \%$ ) to avoid gelification so as to study both dispersions and films. The particle size, distribution, and stability of the colloidal dispersions as well as the physicochemical, thermal, mechanical, and thermomechanical properties, morphology, and hydrophilicity of the films were evaluated and compared to the literature.

\section{EXPERIMENTAL}

\section{Materials}

Waterborne PUU dispersions were synthesized using a difunctional PCL diol and a difunctional PEG (molecular weight from the supplier $M_{n}=2000$ and $1000 \mathrm{~g} \mathrm{~mol}^{-1}$, respectively) as SS, both provided by Sigma-Aldrich. Hydroxyl index, determined by titration according to ASTM D4274-05 was used to determine the molecular weight of the polyols, considering that they are difunctional. As a result, molecular weights of 1957 and $992 \mathrm{~g} \mathrm{~mol}^{-1}$ were obtained for PCL and PEG, respectively. 2,2-Bis(hydroxymethyl)propionic acid (DMPA, 98\% purity) and EDA (99\% purity), used as internal emulsifier and chain extender, respectively, provided also by Sigma-Aldrich, and IPDI (99.5\% purity), supplied from Covestro, were used as HS. Dibutyl tin dilaurate, provided by Sigma-Aldrich, was used as catalyst. The polyols and the DMPA were dried under vacuum at $60^{\circ} \mathrm{C}$ for $4 \mathrm{~h}$ prior to their use. Triethylamine (TEA, 99.5\% purity) was used as neutralizer of the carboxylic groups of DMPA (provided by Fluka) whereas butanone (supplied by Panreac) was used to transfer the neutralized DMPA into the reaction medium and also adjust viscosity.

\section{Synthesis of Waterborne PUUs}

The synthesis of the WBPUU has been carried out using a $250 \mathrm{~mL}$ four-necked flask equipped with a mechanical stirrer, thermometer, condenser, and nitrogen inlet within a thermostatized bath. The synthesis consists on a two-step process where in the former the formation of the prepolymer is carried out, whereas the latter consist on the phase inversion and the chain extension. In the first step of the reaction, PCL, PEG, and IPDI were reacted in bulk at $80{ }^{\circ} \mathrm{C}$ for $3 \mathrm{~h}$ using a $0.1 \mathrm{wt} \%$ of DBTL, and then, the reaction is cooled until $50{ }^{\circ} \mathrm{C}$ where DMPA previously neutralized with TEA diluted in $5 \mathrm{~mL}$ of butanone was added. After $1 \mathrm{~h}$, the system is cooled until room temperature, where the phase inversion step was carried out by adding deionized (DI) water drop by drop, under vigorous stirring; the decrease of temperature before the phase inversion leads to avoid the reaction of the isocyanate with water. Finally, the chain extender (EDA) dissolved previously in DI was added drop by drop at $35^{\circ} \mathrm{C}$ at which the chain extension reaction between the isocyanate groups of the nanoparticles and the diamine-type chain extender is promoted, and left to react for $2 \mathrm{~h}$ to form the final WBPUU. Each step reaction progress was evaluated by dibutylamine back titration method according to ASTM D 2572-97. Once the reaction was completed, the remaining solvent was removed by vacuum distillation at $60{ }^{\circ} \mathrm{C}$. The $\mathrm{pH}$ of the dispersion was measured after the preparation, obtaining values in the range of 7-8 for all samples. Additionally, ionic strength has been calculated for all systems, obtaining values in the range of 0.075-0.078 $\mathrm{mol} \mathrm{L}^{-1}$.

Systems with different SS compositions were prepared, varying the molar ratio of PEG from 0.05 to 0.2 . The theoretical solid content was fixed at $25 \mathrm{wt} \%$ in order to guarantee stable dispersions. All systems were prepared with the molar ratio of polyol/ diisocyanate/emulsifier/chain extender of $1 / 3.5 / 1 / 1.5$. HS content, which is calculated as the percentage of the diisocyanate, emulsifier and chain extender, and the emulsifier percentage remain almost the same for all the synthesized WBPUU. The scheme of the reaction is displayed in Figure 1 whereas the composition of the synthesized WBPUUs is displayed in Table I. The dispersions were storage under room temperature and no presence nor of aggregates nor of deposited material have been observed during time.

\section{Films Preparation}

The dispersions were poured in Teflon molds and dried in a climatic chamber at $25{ }^{\circ} \mathrm{C}$ with a $50 \%$ of relative humidity for 1 week, followed by 3 days in a vacuum oven at $25^{\circ} \mathrm{C}(400-$ 420 mbar). After this time, PU films with a thickness of about $0.5 \mathrm{~m}$ were obtained from WBPUU dispersions. The solid content of the prepared dispersion has been taken into account in order to ensure the desirable thickness of the film. The films have been storage at room temperature in a desiccator in order to keep them away from humidity.

\section{Characterization}

Dynamic Light Scattering. The particle size of the dispersions was measured by dynamic light scattering (DLS) using a BI200SM goniometer, from Brookhaven. The intensity of dispersed light was measured using a luminous source of $\mathrm{He}-\mathrm{Ne}$ laser (Mini L-30, wavelength $=637 \mathrm{~nm}, 400 \mathrm{~mW}$ ) and a detector (BIAPD) placed on a rotary arm which allows measuring the intensity at $90^{\circ}$. Samples were prepared mixing a small amount of the synthesized aqueous dispersion with ultrapure water. Six measurements were performed per system.

Zeta Potential. The stability of the dispersions was analyzed by zeta potential using a ZetaSizer Nano Series ZEN3600, from Malvern Instruments. Samples were prepared diluting the dispersions with ultrapure water.

Solid Content. Solid content was calculated by drying $2 \mathrm{~mL}$ of each dispersion in an oven at $100{ }^{\circ} \mathrm{C}$ for $8 \mathrm{~h}$. The solid content, which was calculated by duplicate, was taken as the ratio between the weight of the dispersion and the weight of the dried sample following eq. (1): 


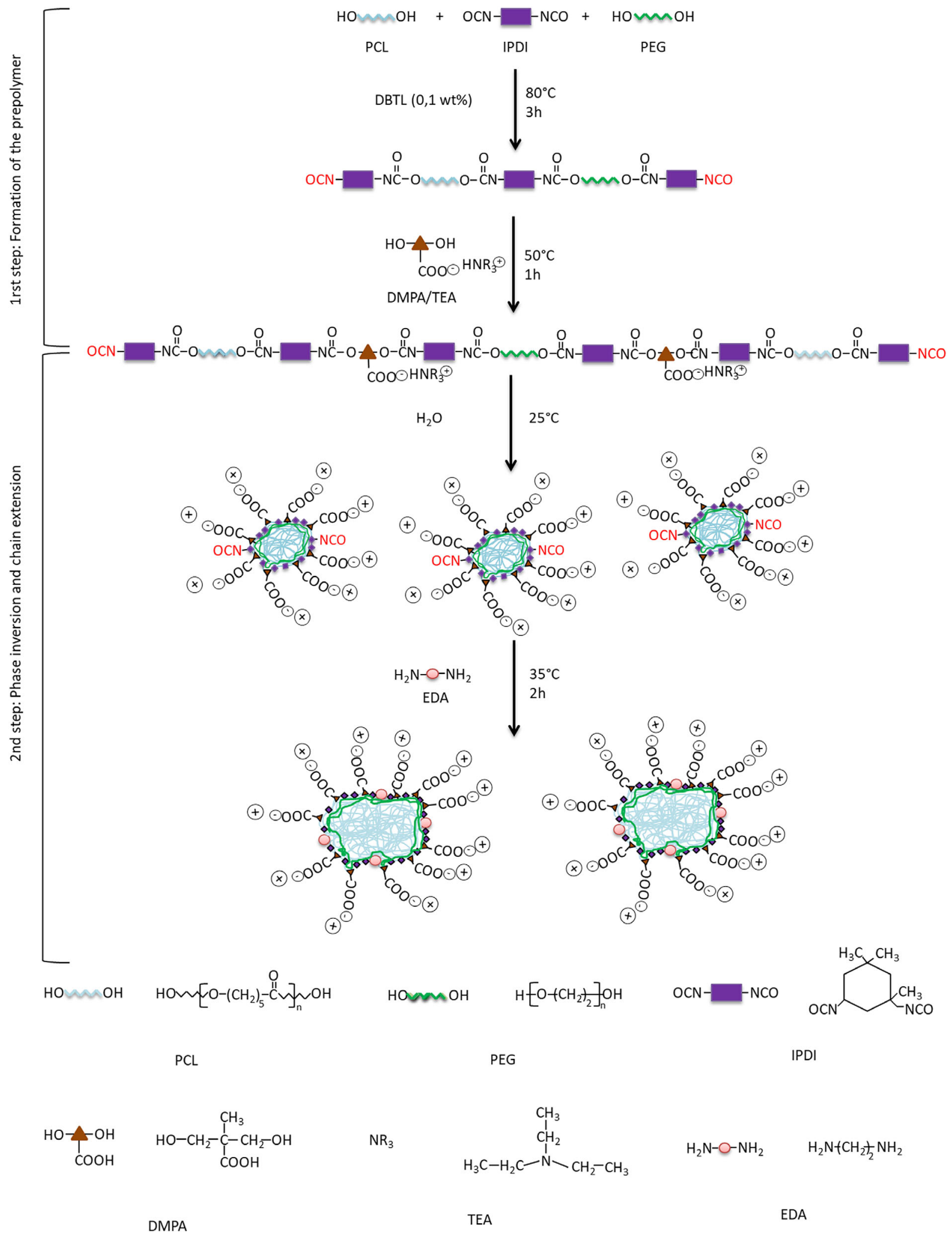

Figure 1. Scheme of the WBPUU synthesis. Synthesis conditions and chemical structure of the reagents. [Color figure can be viewed at wileyonlinelibrary.com]

$$
\% \text { Solid content }=\frac{\text { Dried sample weight }}{\text { Weight of dispersion }} \times 100
$$

Transmission Electron Microscopy. Transmission electron microscopy (TEM) measurements were performed on a TECNAI G2 20 TWIN operated at $80 \mathrm{kV}$ and equipped with LaB6 
filament. Samples used for TEM analysis were diluted into water. A drop of suspension was spread onto a TEM cooper grid (300 Mesh) covered by a pure carbon film and dried at room temperature. The grid was glow discharged before put the drop of suspension.

Gel Permeation Chromatography. Weight-average molecular weight $\left(M_{w}\right)$ and dispersity $(\boxplus)$ of the prepared films were determined by gel permeation chromatography (GPC) using a Thermo Scientific chromatograph, equipped with an isocratic Dionex UltiMate 3000 pump and a RefractoMax 521 refractive index detector. The separation was carried out at $30{ }^{\circ} \mathrm{C}$ within four Phenogel GPC columns from Phenomenex with $5 \mu \mathrm{m}$ particle size and 105, 103, 100, and $50 \AA$ porosities, respectively, located in an UltiMate 3000 thermostated column compartment. Tetrahydrofuran (THF) was used as mobile phase at a flow rate of

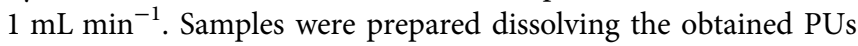
films by casting in THF at 1 wt \% and filtering using nylon filters with $2 \mu \mathrm{m}$ pore size. $M_{w}$ and $Ð$ were reported as weight-average polystyrene standards.

Water Contact Angle Measurement. Static water contact angle (WCA) of the surface of the film was measured using a Phoenix300 goniometer of SEO. For the measurement, drops of DI water of $0.1 \mu \mathrm{L}$ have been used. Ten measurements were performed per sample.

Fourier Transform Infrared Spectroscopy. The characteristic functional groups of WBPUUs were analyzed by Fourier transform infrared (FTIR) using Nicolet Nexus spectrometer provided with a MKII Golden Gate accessory (Specac) with a diamond crystal at a nominal incidence angle of $45^{\circ}$ and $\mathrm{ZnSe}$ lens. Spectra were recorder in attenuated total reflection (ATR) mode between 4000 and $650 \mathrm{~cm}^{-1}$ averaging 64 scans with a resolution of $8 \mathrm{~cm}^{-1}$.

Proton Nuclear Magnetic Resonance. The chemical structure of WBPUUs was analyzed by proton nuclear magnetic resonance $\left({ }^{1} \mathrm{H}\right.$ NMR). The measurement was carried out in a Bruker Avance 500 spectrometer, equipped with a BBO probe with gradient in $z$ axis and using a resonant frequency of $125.77 \mathrm{MHz}$. Acquisition times were established at $3 \mathrm{~s}$ averaging $64 \mathrm{~K}$ scans, using an interpulse delay of $2 \mathrm{~s}$. A time domain of $64 \mathrm{~K}$ was used in a spectral width of $10,000 \mathrm{~Hz}$.

Differential Scanning Calorimetry. The thermal properties of the films were determined by differential scanning calorimetry (DSC) using Mettler Toledo 822 equipment provided with a robotic arm and an electric intracooler as refrigerator unit. Between 5 and $10 \mathrm{mg}$ of samples were encapsulated in aluminum pans and heated from -50 to $200{ }^{\circ} \mathrm{C}$ at a scanning rate of $10^{\circ} \mathrm{C} \mathrm{min}^{-1}$ in nitrogen atmosphere.

X-ray Diffraction. X-ray powder diffraction patterns were collected by using a Philips X'pert PRO automatic diffractometer operating at $40 \mathrm{kV}$ and $40 \mathrm{~mA}$, in theta-theta configuration, secondary monochromator with $\mathrm{Cu} \mathrm{K \alpha}$ radiation $(\lambda=1.5418 \AA$ ) and a PIXcel solid-state detector (active length in $2 \theta=3.347^{\circ}$ ). 
Data were collected from 5 to $75^{\circ} 2 \theta$ (step size 0.026 and time per step $=80 \mathrm{~s}$ ) at room temperature. A fixed divergence and antiscattering slit giving a constant volume of sample illumination were used.

Thermogravimetric Analysis. The thermal stability of the films was determined by thermogravimetric analysis (TGA) using a Mettler Toledo equipment. Between 5 and $10 \mathrm{mg}$ of samples were introduced in ceramic pans. The samples were heated from 25 to $800^{\circ} \mathrm{C}$ in nitrogen atmosphere at a scanning rate of $10{ }^{\circ} \mathrm{C} \min ^{-1}$.

Thermomechanical Analysis. The thermomechanical behavior of the films was determined by using an Eplexor $100 \mathrm{~N}$ analyzer Gabo equipment. The measurements were carried out in tensile mode from -100 to $150{ }^{\circ} \mathrm{C}$ at a constant scanning rate of $2{ }^{\circ} \mathrm{C} \min ^{-1}$ and a fixed frequency equal to $1 \mathrm{~Hz}$. The constant strain was established as $0.05 \%$ to keep the linear behavior.

Mechanical Testing. Tensile analysis was performed on an Instron 5967 testing machine provided with a $500 \mathrm{~N}$ load cell and pneumatic grips to hold the samples. Samples were cut in strips of $2.8 \mathrm{~mm}$ in width and $0.5 \mu \mathrm{m}$ in thickness and tested at a constant rate of $20 \mathrm{~mm} \mathrm{~min}^{-1}$ at room temperature with a distance between clamps of $10 \mathrm{~mm}$. Young modulus $(E)$, stress at break $\left(\sigma_{b}\right)$, and strain at break $\left(\varepsilon_{b}\right)$ were averaged from stressstrain curves of eight specimens of each series.

Atomic Force Microscopy. The morphology of the different WBPUU systems was analyzed by atomic force microscopy (AFM) in tapping mode, using a Nanoscope IIIa scanning probe microscope (MultimodeTM Digital Instruments) with an integrated force generated by cantilever/silicon probes, applying a resonance frequency of about $180 \mathrm{kHz}$. The cantilevers were $125 \mu \mathrm{m}$ long and had a tip radius of 5-10 nm. Samples were prepared by drying a drop of PUU dispersion on glass supports via spin coating (Spincoater P6700) at $200 \mathrm{rpm}$ for $130 \mathrm{~s}$. Height and phase images were taken simultaneously.

\section{RESULTS AND DISCUSSION}

\section{Dispersions Characterization}

The particle size of the synthesized WBPUU dispersions and their average diameter measured by DLS, the zeta-potential measurements as well as the real solid content are summarized in Table II.
DLS reveals a particle size of $86 \pm 0.1 \mathrm{~nm}$ for the PCL100 system, with a polydispersity of $0.05 \pm 0.02$; these results are similar to those reported by other authors, which reported values in the range between 70 and $100 \mathrm{~nm} .{ }^{33}$ Comparing this obtained particle size with the dispersions containing PEG, an increase of both particle size and polydispersity can be observed. The hydrophilic nature of PEG allows the swelling of the particles by interactions with water; thus, the particle present not only higher particle size, but also higher polydispersity with all systems presenting monomodal distributions with the absence of aggregates. This increase of the particle size leads to the reduction of the specific surface area, ${ }^{41-43}$ which can affect to the stability of the dispersion; however, in this case, no modification of the stability was observed as the particle size increased.

As far as the stability of the dispersions is concerned, all the systems present zeta potentials below $-30 \mathrm{mV}$, so hence, the stability of the prepared dispersions is proved since stable dispersions have a zeta potential above $+30 \mathrm{mV}$ and below $-30 \mathrm{mV} .{ }^{44}$ The solid content was also determined by the aforementioned method. The synthesized WBPUUs showed a solid content close to the theoretical, suggesting that all the reagents were adequately integrated in the stable nanoparticles. The WBPUU dispersions were stored under room temperature and no presence nor of aggregates nor of sediment material has been observed during time.

The dispersions were also analyzed by TEM. Images of the WBPUUs with different PEG contents are shown in Figure 2. The obtained images confirm the higher particle size of the WBPUUs containing PCL/PEG in their SS compared with the WBPUU based on PCL. Additionally, the hydrophilic PEG in the SS tends to arrange at the nanoparticle shell. As can be observed in the inset of each image, at the intermediate PEG content the core and the shell start begin to differentiate and at the highest PEG content, a more defined core-shell structure seems to be observed in PCL80PEG20 system, suggesting that the addition of PEG promotes structural changes into the nanoparticle.

\section{Films Characterization}

The molecular weight of the films was determined by gel permeation chromatography. The obtained results are displayed in Table III. Results showed that PCL100 is the WBPUU with the higher molecular weight. The addition of PEG results into lower molecular weight, probably owing to the lower molecular weight of PEG polyol (992 $\mathrm{g} \mathrm{mol}^{-1}$ ) compared with PCL polyol $\left(1957 \mathrm{~g} \mathrm{~mol}^{-1}\right)$. This decrease of molecular weight is noticeable and greater in systems with higher amounts of PEG. Similar

Table II. Characterization of the WBPUU Dispersions

\begin{tabular}{lcccc}
\hline Sample & Particle size $(\mathrm{nm})$ & Polydispersity & Zeta potential $(\mathrm{mV})$ & Solid content $(w t$ \%) \\
\hline PCL100 & $86 \pm 1$ & $0.05 \pm 0.02$ & $-44.2 \pm 0.3$ & 25.02 \\
PCL95PEG5 & $97 \pm 0.5$ & $0.16 \pm 0.01$ & $-48.7 \pm 0.9$ & 23.25 \\
PCL90PEG10 & $115 \pm 2$ & $0.26 \pm 0.03$ & $-41.6 \pm 0.2$ & 25.18 \\
PCL85PEG15 & $105 \pm 5$ & $0.23 \pm 0.03$ & $-44.1 \pm 0.9$ & 24.50 \\
PCL80PEG20 & $112 \pm 15$ & $0.13 \pm 0.05$ & $-42.7 \pm 0.6$ & 26.20 \\
\hline
\end{tabular}



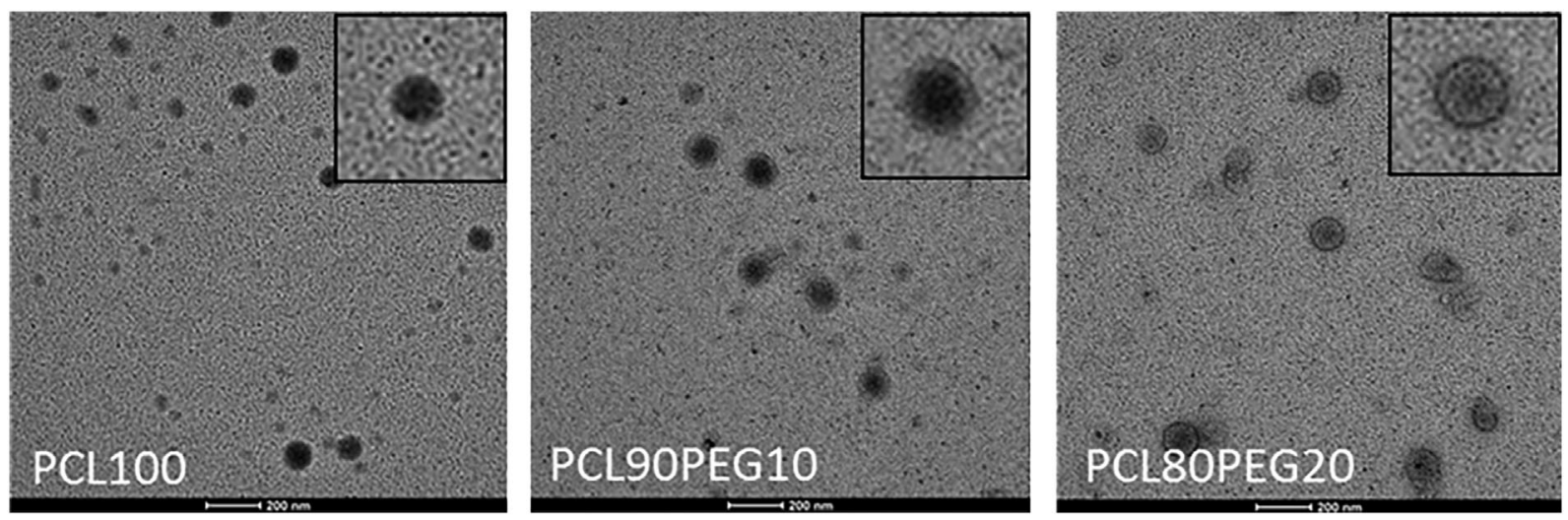

Figure 2. TEM images of different WBPUU systems. $\times 2500$ magnification. Evolution of particle size and structure with the PEG content.

molecular weight values are reported in the literature for waterborne PUs containing PEG in their SS, obtaining values between 25,000 and $15,000 \mathrm{~g} \mathrm{~mol}^{-1}$ with different contents of PEG. ${ }^{32}$ Despite this decrease, the aforementioned measured $\mathrm{pH}$ range of $7-8$, confirmed that the reaction has been performed successfully. Regarding dispersity, all system present similar values with the addition of PEG but higher compared with systems only containing PCL. Additionally, the hydrophilic-hydrophobic nature of the surface of the prepared films has been determined by WCA measurement (Table III). Analyzing the obtained values, the addition of hydrophilic PEG to the WBPUUs resulted in a decrease of the contact angle as expected from the hydrophilic PEG shell observed for the particles. In films with higher amount of PEG it tends to arrange in the shell of the particle, showing more affinity with water compared with systems based only on PCL or with small amounts of PEG.

The characteristics functional groups of PUs were studied by FTIR. Figure 3(a) shows the FTIR spectra of the WBPUU synthesized with only PCL in the SS, PCL100, and the WBPUU synthesized with the highest content of PEG, PCL80PEG20. Both spectra show a peak in the $3350-3320 \mathrm{~cm}^{-1}$ interval, where hydrogen-bonded and nonhydrogen-bonded $\mathrm{N}-\mathrm{H}$ of urethane and urea groups appear. ${ }^{4}$ In this case, the observed signal, situated at $3330 \mathrm{~cm}^{-1}$ suggests that most of the $\mathrm{N}-\mathrm{H}$ groups are involved in hydrogen bonds. The peak around $1735 \mathrm{~cm}^{-1}$ corresponds to the $\mathrm{C}=\mathrm{O}$ vibration of $\mathrm{PCL}$ and urethane group, ${ }^{45}$ whereas a signal situated at $1640 \mathrm{~cm}^{-1}$ is attributed to hydrogen bonded $\mathrm{C}=\mathrm{O}$ of urea groups. ${ }^{46}$ The peak situated at $1550 \mathrm{~cm}^{-1}$ in Amide II region is assigned to the $\mathrm{C}-\mathrm{N}$ stretching vibration

Table III. Weight-Average Molecular Weight and Dispersity of Synthesized WBPUU with Different Ratios of PEG/PCL and WCAs of the Films

\begin{tabular}{llll}
\hline Sample & $\begin{array}{l}\overline{\mathrm{M}}_{w} \\
\left(\mathrm{~g} \mathrm{~mol}^{-1}\right)\end{array}$ & $\begin{array}{l}\text { Dispersity } \\
\left(\overline{\mathrm{M}}_{\mathrm{w}} / \overline{\mathrm{M}}_{\mathrm{n}}\right)\end{array}$ & $\begin{array}{l}\text { Contact } \\
\text { angle }\left(^{\circ}\right)\end{array}$ \\
\hline PCL100 & 35,240 & 1.3 & $90 \pm 3$ \\
\hline PCL95PEG5 & 25,795 & 1.5 & $83 \pm 3$ \\
PCL90PEG10 & 24,314 & 1.7 & $78 \pm 3$ \\
PCL85PEG15 & 23,196 & 1.7 & $76 \pm 2$ \\
PCL8OPEG20 & 21,813 & 1.8 & $72 \pm 4$ \\
\hline
\end{tabular}

and $\mathrm{N}-\mathrm{H}$ bending of urethane groups. The band located around $1460 \mathrm{~cm}^{-1}$ corresponds to $-\mathrm{CH}_{2}-$ stretching band and the signal situated at $1024 \mathrm{~cm}^{-1}$ is assigned to $\mathrm{C}-\mathrm{O}$ stretching vibration. Additionally, the absence of bands in the $2260-2280 \mathrm{~cm}^{-1}$ interval (-NCO group) confirmed that the diisocyanate had completely reacted during the synthesis, and thus, means that the polymerization reaction has happened successfully. ${ }^{47}$ Comparing both spectra, no differences were observed, neither shifting of existing bands nor apparitions of new signals have been observed despite of their different SS compositions.

The chemical structure of the prepared WBPUUs was also analyzed by ${ }^{1} \mathrm{H}$ NMR. Spectra displayed in Figure 3(b) showed differences between PCL100 and PCL80PEG20 WBPUUs. Spectrum of PCL100 showed typical chemical shifts related to the different protons of PCL polyol at $4.06(\mathrm{Ha}), 2.4(\mathrm{Hb}), 1.67(\mathrm{Hc})$, and 1.36 (Hd) ppm. The spectrum of PCL80PEG20, in addition to peaks of PCL, showed a peak at $3.6 \mathrm{ppm}$, which is assigned to the methylene protons of the backbone of PEG $(\mathrm{He})$. The presence of this new signal confirms the incorporation of the PEG. A peak related with methylene protons of DMPA at $3.9 \mathrm{ppm}(\mathrm{Hf})$ is also observed in both spectra. Taking into account the molecular weight of both polyols and the areas of Ha peak of PCL and He peak of PEG, the PEG content in PCL80PEG20 WBPUU is determined, obtaining a value of 0.22 which is similar to the theoretical.

Thermal behavior of the films has been studied by DSC. The thermograms of synthesized WBPUUs and neat polyols for comparison purposes are displayed in Figure 4 and the values of the calculated transitions are displayed in Table IV. A transition was observed in all samples around $-55{ }^{\circ} \mathrm{C}$, which is related with the transition of the SS ( $\left.T_{g} \mathrm{SS}\right)$. Comparing to the glass-transition temperature of pure polyols, an increase was observed respect to PCL $T_{g}$ at $-66.7^{\circ} \mathrm{C}$ (no $T_{g}$ was observed for PEG in this interval), due to mobility restrictions when they were integrated in the PU structure. In addition, no melting peaks of SS were observed, which indicates that this integration prevents PCL or PEG rich domains crystallization. Neat PEG and PCL showed a melting peak at 42.7 and $46.7^{\circ} \mathrm{C}$, respectively. X-ray diffraction analysis has been performed in order to confirm the lack of SS crystallization. The obtained results that are displayed on the inset of Figure 4 does not show any signs of crystallization in all studied 
WBPUUs agreeing with DSC results. Regarding the HS, an endothermic transition can be observed in all samples in the $70-80^{\circ} \mathrm{C}$ interval attributed to the short-range ordering HS domains. ${ }^{48}$ This endothermic transition temperature measured for PCL100 is in the range of the values reported previously for other WBPUUs containing only PCL in the SS. ${ }^{18}$ The temperature of this transition seems to decrease with the addition of PEG. Additionally, the enthalpy assigned to this phenomenon also seems to be lower with the addition of PEG. The tendency of PEG to arrange in the shell of nanoparticles could hinder the ability of interactions between urethane-urea groups in the HS, thus resulting in a decrease of both melting temperature and enthalpy. This decrease is more appreciable starting from a $3.4 \mathrm{wt} \%$ of PEG.
The thermal stability of WBPUU has been studied by TGA. The thermal degradation of PUUs is believed to be a depolycondensation process which starts above $200{ }^{\circ} \mathrm{C}$ with the degradation of HSs, and finished with the degradation of the soft ones. ${ }^{49}$ In general, it consists on a first two degradations corresponding to urea and urethane linkages around 250 and $300{ }^{\circ} \mathrm{C}$, respectively, and a third one around $350-400{ }^{\circ} \mathrm{C}$ assigned to the SS. ${ }^{50}$ However, the temperature of the different degradation steps can be modified since the thermal stability of the PUUs is highly depending on the composition of the hard and SS, the type of diisocyanate, the ionic group content as well as the microphase separation and crystallinity of the phases. ${ }^{51}$ The TGA and DGT curves of the WBPUUs and polyols are displayed in

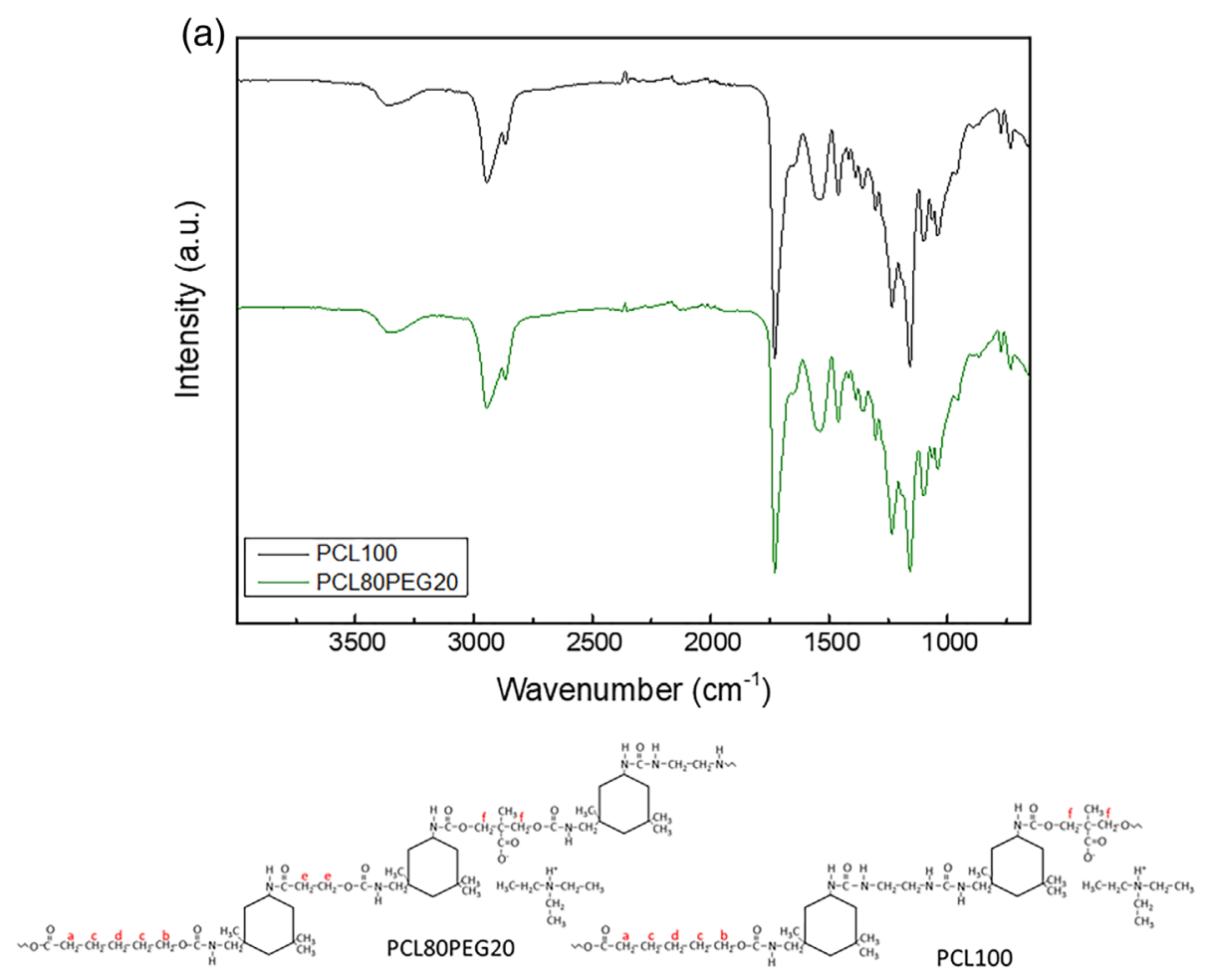

(b)
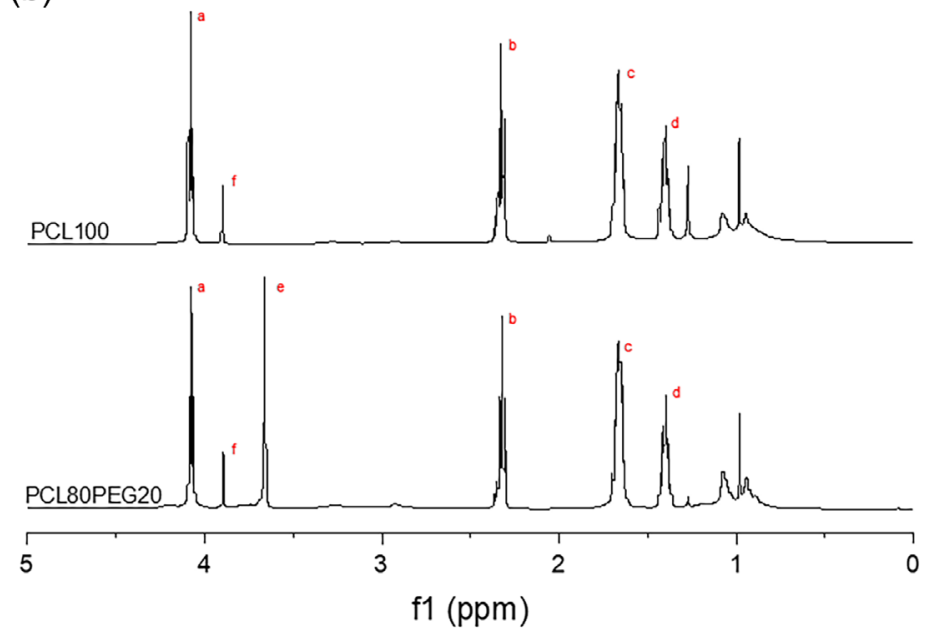

Figure 3. (a) ATR-FTIR spectra of PCL100 and PCL80PEG20 (up) and (b) ${ }^{1} \mathrm{H}$ MNR spectra of PCL100 and PCL80PEG20 (down). [Color figure can be viewed at wileyonlinelibrary.com] 
Figure 5. Analyzing the obtained results, PCL-based PUU showed one degradation step around $300{ }^{\circ} \mathrm{C}$, whereas WBPUUs containing PEG also showed a second degradation step around $375^{\circ} \mathrm{C}$. Comparing with the TGA and DTG curves of neat PCL and PEG, a higher degradation temperature of PEG compared with PCL is observed; so, the second degradation appeared in PCL/PEG containing WBPUUs seems to correspond to the PEG. The obtained behavior does not correspond with the aforementioned general behavior, since the steps assigned to urea and urethane linkages and PCL polyol are overlapped in a single degradation process. Thermal stability of this WBPUU films is an important parameter in order to determine the potential applications of this material; all systems were stable until $250{ }^{\circ} \mathrm{C}$ where the first degradation process happens; however, the endothermic transition observed at $70-80{ }^{\circ} \mathrm{C}$ in the DSC thermogram, for all systems, limits clearly the operational stability below this temperature. The prepared materials could be reuse by reprocessing the films above their melting temperature.

Regarding the thermomechanical properties, the evolution of storage modulus $\left(E^{\prime}\right)$, loss modulus $\left(E^{\prime \prime}\right)$ and $\tan \delta$ with temperature of the different WBPUUs have been determined by dynamic mechanical analysis (DMA), and the obtained results of the different systems are presented in Figure 6. As can be seen, the PCL100 WBPUU showed the higher storage modulus at glassy state. The decrease in $E^{\prime}$ and the maximum of $\tan \delta$ and $E^{\prime \prime}$ observed at low temperatures are related to the glass-transition temperature of the SS. For all the synthesized WBPUUs, the addition of PEG does not significantly change the $T_{g}$ SS as also observed by DSC. Notwithstanding, a flattening and broadening of the $\tan \delta$ peak is observed at the highest PEG content, owing to the restrictions in the molecular mobility from PEG chains assembled in the nanoparticles shell. Above $T_{g}$ SS all systems showed a decreasing of the elasticity part $E^{\prime}$, presenting PCL100 and PCL95PEG5 higher modulus at room temperature. Similar behaviors were observed in the literature with maximum $\tan \delta$ values, which is related with the $T_{g} S S$, in the same interval. ${ }^{13,18,36}$

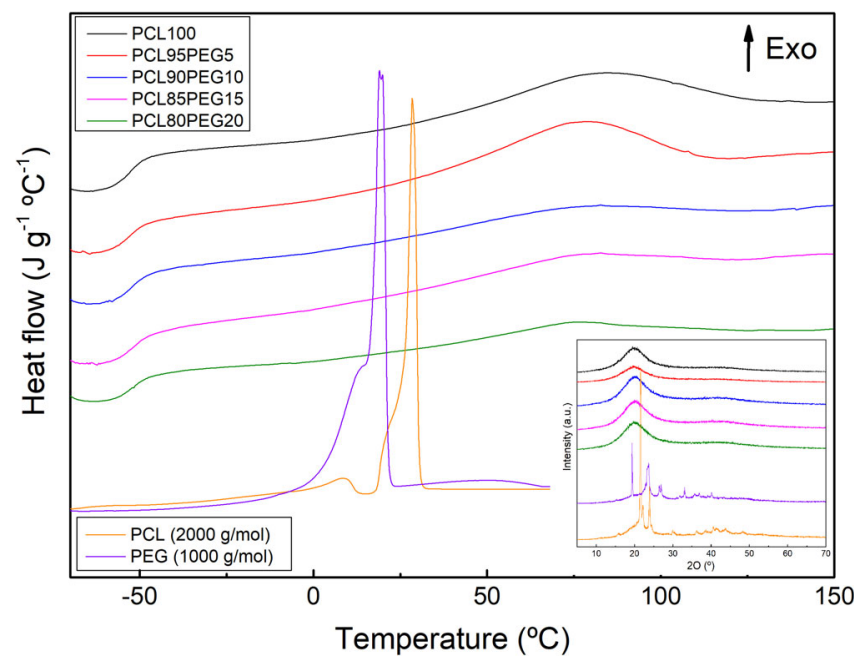

Figure 4. DSC thermograms of synthesized WPUU films and pure polyols. Inset: X-ray diffractograms of WBPUUs and pure polyols. [Color figure can be viewed at wileyonlinelibrary.com]
Table IV. Calculated Thermal Transitions of WBPU Films

\begin{tabular}{llll}
\hline Sample & $T_{g} \mathrm{SS}\left({ }^{\circ} \mathrm{C}\right)$ & $T_{m} \mathrm{HS}\left({ }^{\circ} \mathrm{C}\right)$ & $\Delta H_{m} \mathrm{HS}\left(\mathrm{J} \mathrm{g}^{-1}\right)$ \\
\hline PCL100 & -55.9 & 79.5 & 16.5 \\
PCL95PEG5 & -56.8 & 78.0 & 15.8 \\
PCL90PEG10 & -56.5 & 74.2 & 6.1 \\
PCL85PEG15 & -55.6 & 73.5 & 5.5 \\
PCL80PEG20 & -55.1 & 72.8 & 3.4 \\
\hline
\end{tabular}

As far as the thermomechanical stability is concerned, the addition of PEG seems to decrease the thermomechanical stability compared to the PCL-based polymer (PCL100). Both PCL100 and PCL95PEG5 showed higher stabilities whereas the other systems containing more amount of PEG experienced a significant decrease, showing a progressive drop of their $E^{\prime}$ and $E^{\prime \prime}$ at lower temperatures. The assembly of the PEG into the shell of the particles hampers the formation of short-range interactions between urethane-urea groups.
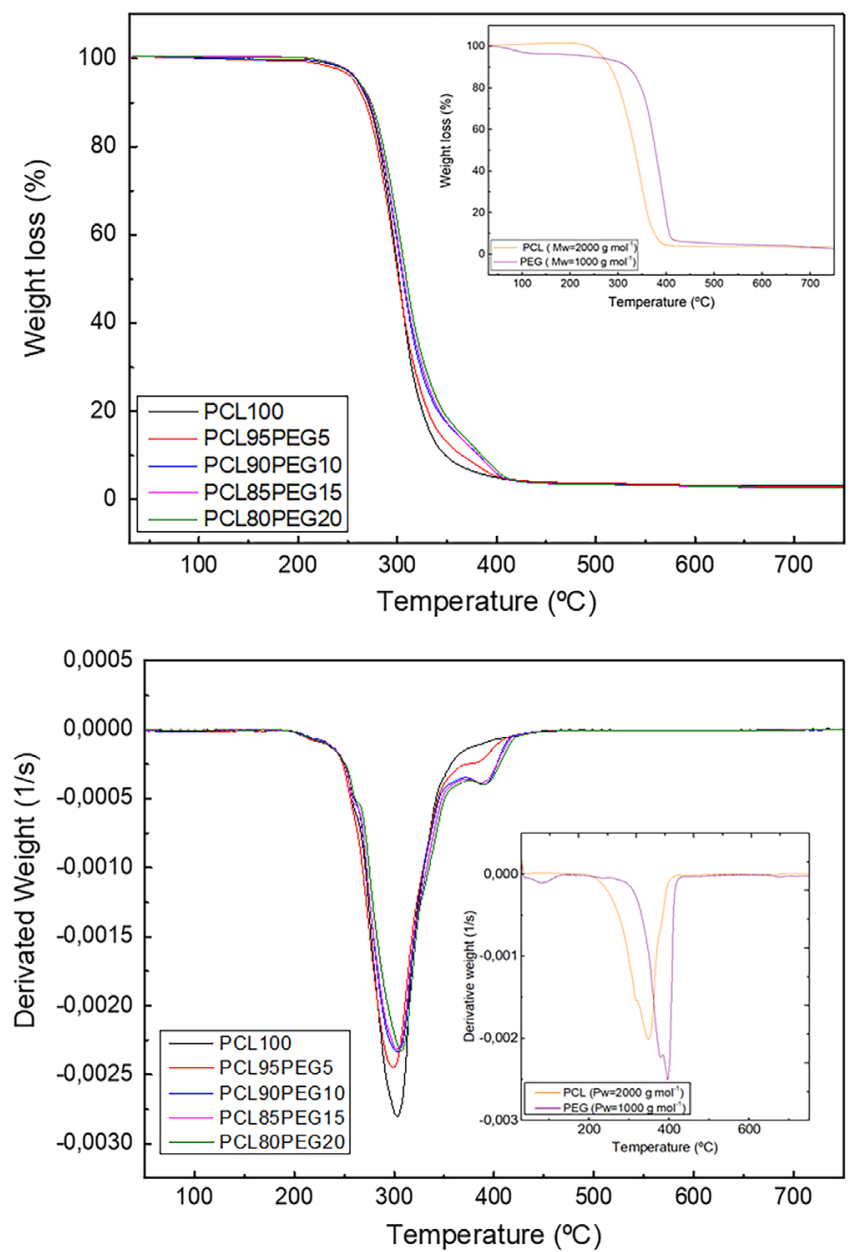

Figure 5. Variation of the weight (up) and the derivated weight (down) of the WBPUU as a function of the temperature. Weight loss of polyols (inside up) and derivated weight of polyols (inside down) have been included for comparative purposes. [Color figure can be viewed at wileyonlinelibrary.com] 


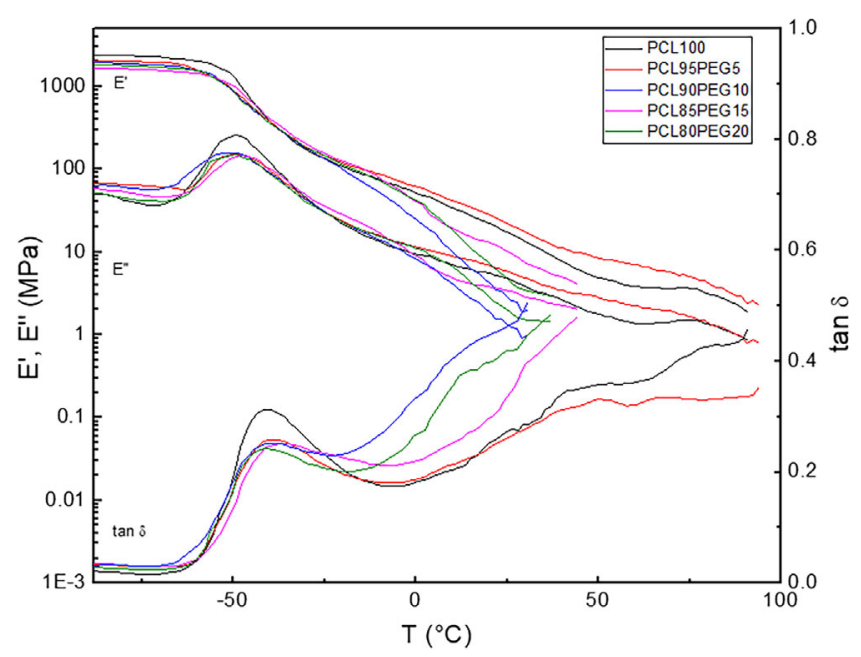

Figure 6. Storage and loss modulus (left) and $\tan \delta$ (right) as a function of temperature for PCL/PEG PUU systems. Frequency $=1 \mathrm{rad} \mathrm{s}^{-1}$ and scanning rate $=2^{\circ} \mathrm{Cmin}^{-1}$. [Color figure can be viewed at wileyonlinelibrary.com]

Mechanical properties of the WBPUU were evaluated by tensile testing. Figure 7 shows the stress-strain curves of the different systems, whereas mechanical parameters such as Young modulus, tensile stress, and elongation at break are summarized in Table V. The behavior of the different systems agrees with previous DSC and thermomechanical analysis results. A decrease of the urethane and urea short-range ordering in the HS with the addition of PEG results in lower tensile modulus and stress at break, but higher strain at break. Similar thermal and mechanical behaviors were found for PCL100 and PCL95PEG5 WBPUUs. Comparing these values with those reported in previous works, one can notice higher values of Young modulus $(23 \pm 2 \mathrm{MPa}$ against $6.4 \pm 0.4 \mathrm{MPa}$ ), as well as similar strain at breaks $(842 \pm 102 \%$ vs. $891 \pm 51 \%){ }^{38}$ Other systems presenting higher amount of PEG exhibited similar Young modulus values as well

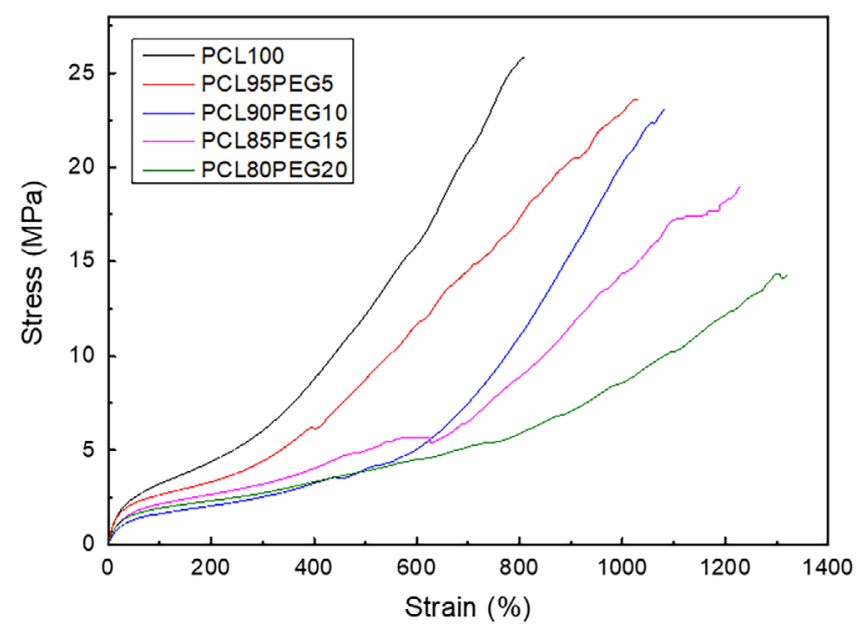

Figure 7. Stress-strain curves of WBPUUs at room temperature. Elongation rate $=20 \mathrm{~mm} \mathrm{~min}^{-1}$. [Color figure can be viewed at wileyonlinelibrary.com]
Table V. Mechanical Properties of WBPUU Films

\begin{tabular}{llll}
\hline & $\begin{array}{l}\text { Young } \\
\text { modulus } \\
(E)(\mathrm{MPa})\end{array}$ & $\begin{array}{l}\text { Stress at } \\
\text { break } \\
\left(\sigma_{b}\right)(\mathrm{MPa})\end{array}$ & $\begin{array}{l}\text { Strain at } \\
\text { break } \\
\left(\varepsilon_{b}\right)(\%)\end{array}$ \\
\hline PCL100 & $21 \pm 2$ & $29 \pm 8$ & $842 \pm 102$ \\
\hline PCL95PEG5 & $19 \pm 2$ & $25 \pm 3$ & $1063 \pm 114$ \\
\hline PCL90PEG10 & $14 \pm 2$ & $24 \pm 8$ & $1080 \pm 41$ \\
PCL85PEG15 & $14 \pm 2$ & $15 \pm 5$ & $1106 \pm 122$ \\
PCL80PEG20 & $14 \pm 2$ & $12 \pm 5$ & $1312 \pm 84$ \\
\hline
\end{tabular}

as similar strain at break suggesting that the addition of only $3.4 \mathrm{wt} \%$ is enough to modify the behavior of the WBPUU. Moreover, it is important to indicate that no remarkable differences were observed at higher PEG content.

AFM analysis was carried out in order to analyze the morphology of films formed from the dispersions. Figure 8 shows the phase and three-dimensional representation of height images of different PUU systems. High dissipating soft domains give dark contrast while stiffer phases appear brighter due to the different energy dissipation by the cantilever, enabling the possibility of differentiate the different domains. ${ }^{52}$ Analyzing the obtained images, separated microphase segregation can be observed in PCL100 system. These phases, which are formed by the coalescence of the nanoparticles, thus presenting a spherical microstructure, are formed by dark domains corresponding to the core PCL and lighter zones, which are composed by the HS and represent the shell of the particles. The formation of these microdomains leads to better mechanical properties as well as higher thermomechanical stability as was obtained in mechanical testing and DMA. The addition of PEG to the WBPUU, however, seems to result into a modification of the morphology which can be observed with the addition of very small quantities of PEG (3.4 wt \%); above this quantity, no remarkable differences are observed in the morphology. Due to its hydrophilic nature, the PEG tends to arrange at the shell of the particle, becoming slightly thicker, as was also observed by TEM. As can be observed for the WBPUU with the highest amount of PEG, the thick of the particles shell increases whereas the dark domains corresponding to the PCL decrease their size, leading to the formation of a slightly different microstructure to that observed in PCL100. Hence, PCL90PEG10 and PCL80PEG20 present similar morphology as was also observed by TEM, both due to the arrangement of PEG in the shell of the particles. The analyzed microstructures corroborate that hydrophilic PEG act as nonionic emulsifier facilitating the formation of the nanoparticles.

It can conclude that the morphology changes observed by AFM as well as the core-shell morphology highlighted by TEM both confirm the assembly of PEG in the shell of the particle. This result into a hamper of the formation of short-range ordering between urea and urethanes, which leads to systems with different mechanical, thermal, and thermomechanical properties. Above this modification of the properties, the inclusion of the PEG to the backbone eases the transformation of the dispersion 

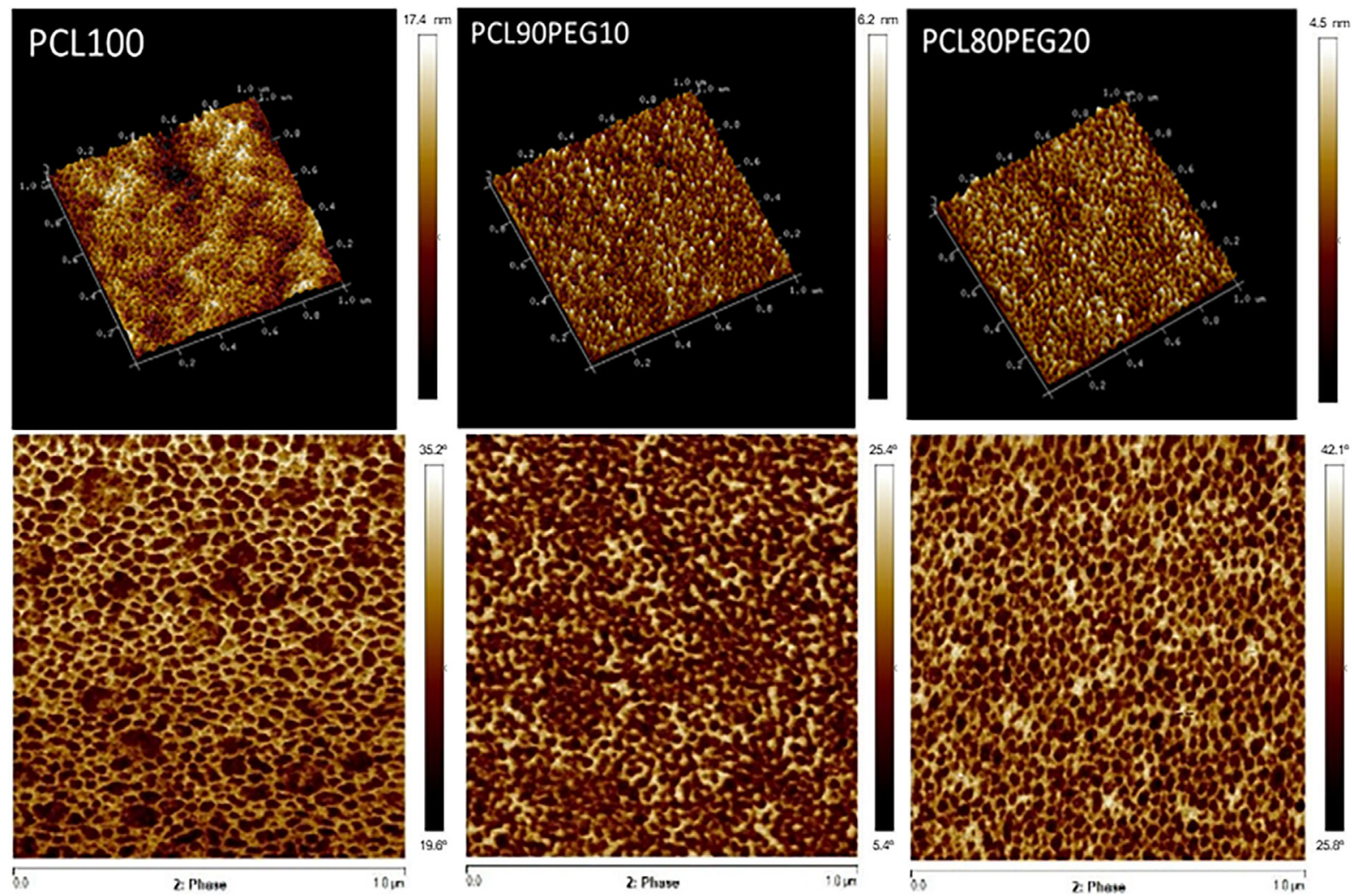

Figure 8. AFM 3D height reconstruction and phase images of PCL100, PCL90PEG10, and PCL80PEG20 WBPUUs. [Color figure can be viewed at wileyonlinelibrary.com]

into a physical gel, which opens the possibility of using these materials in other fields such as the biomedical one widening the application field of this type of materials.

\section{CONCLUSIONS}

In this work, stable waterborne PUU (WBPUU) dispersions varying PCL/PEG molar ratio in the SS were successfully synthesized. The increase of the PEG content in the WBPUU resulted into an increase of the particle size and polydispersity, obtaining values of $112 \pm 15$ for PCL80PEG20 compared with the $86 \pm 1$ of PLC100. Moreover, zeta-potential measurements confirmed the stability of all dispersions. The particle morphology analyzed by TEM revealed that the addition of PEG led to a more segregated core-shell structure which is not observed in PCL100 particles. Regarding film properties, PCL100 system showed higher Young modulus, thermomechanical stability, and higher enthalpy assigned to the short-range ordering of hard domains due to the microstructure observed in that system. Systems containing PEG in their SS, however, showed higher elongation at break owing to the observed microstructure where PEG hampers the formation of short-range ordered domains between urea and urethanes. Concretely, the elongation at break increased 500\% comparing the PCL100 system with the one containing the higher amount of PEG. Additionally, films containing hydrophilic PEG present also higher affinity with water obtaining decreasing WCAs when PEG is added, from $90 \pm 3$ of PCL100 to72 \pm 4 of PCL80PEG20.
Finally, a low amount of $3.4 \mathrm{wt} \%$ of PEG is enough to modify the properties and higher PEG content does not result in a noticeable variation of the properties of films.

\section{ACKNOWLEDGMENTS}

Financial support from the University of the Basque Country (UPV/EHU) (GIU18-216) and Spanish Ministry of Economy and Competitiveness (MINECO) (MAT2016-76294R) are gratefully acknowledged. J.V. wishes to acknowledge both the University of Pau and Pays de l'Adour and the UPV/EHU for his PhD grant. Moreover, technical support provided by "MacrobehaviourMesostructure-Nanotechnology" and "Microscopy: Polymer characterization" SGIker units from the UPV/EHU are also gratefully acknowledged.

\section{REFERENCES}

1. Marzec, M.; Kucińska-Lipka, J.; Kalaszczyńska, I.; Janik, H. Mater. Sci. Eng. C. 2017, 80, 736.

2. Joo, Y. S.; Cha, J. R.; Gong, M. S. Mater. Sci. Eng. C. 2018, $91,426$.

3. Akindoyo, J. O.; Beg, M. D. H.; Ghazali, S.; Islam, M. R.; Jeyaratnam, N.; Yuvaraj, A. R. RSC Adv. 2016, 6, 114453.

4. Yilgör, I.; Yilgör, E.; Wilkes, G. L. Polymers. 2015, 58, A1.

5. Chattopadhyay, D. K.; Raju, K. V. S. N. Prog. Polym. Sci. 2007, 32, 352. 
6. Adoption of the Paris Agreement. Decision 1/CP.21 UN Framework Convention on Climate Change. 2015.

7. Zhang, X.; Zhu, M.; Wang, W.; Yu, D. Prog. Org. Coat. 2018, 120, 10.

8. Feng, J.; Ge, Z.; Chai, C.; Wang, S.; Yu, D.; Wu, G.; Luo, Y. Prog. Org. Coat. 2016, 97, 91.

9. Yoon Jang, J.; Kuk Jhon, Y.; Woo Cheong, I.; Hyun Kim, J. Colloids Surf. A Physicochem. Eng. Asp. 2002, 196, 135.

10. Noreen, A.; Zia, K. M.; Zuber, M.; Tabasum, S.; Saif, M. J.; Korean, J. Chem. Eng. 2016, 33, 388.

11. Li, B.; Peng, D.; Zhao, N.; Mu, Q.; Li, J. J. Appl. Polym. Sci. 2013, 127, 1848.

12. Lei, L.; Zhong, L.; Lin, X.; Li, Y.; Xia, Z. Chem. Eng. J. 2014, 253, 518.

13. Díez-García, I.; Santamaría-Echart, A.; Eceiza, A.; Tercjak, A. Eur. Polym. J. 2018, 99, 240.

14. Bullermann, J.; Friebel, S.; Salthammer, T.; Spohnholz, R. Prog. Org. Coat. 2013, 76, 609.

15. Li, F.; Luo, S.; Ma, C.; Yu, J.; Cao, A. J. Appl. Polym. Sci. 2010, 118, 623.

16. Cakic, S. M.; Stamenkovic, J. V.; Djordjevic, D. M.; Ristic, I. S. Polym. Degrad. Stab. 2009, 94, 2015.

17. Król, P. Prog. Mater. Sci. 2007, 52, 915.

18. Santamaria-Echart, A.; Fernandes, I.; Saralegi, A.; Costa, M. R. P. F. N.; Barreiro, F.; Corcuera, M. A.; Eceiza, A. J. Colloid Interface Sci. 2016, 476, 184.

19. Santamaria-Echart, A.; Arbelaiz, A.; Saralegi, A.; Fernández-d'Arlas, B.; Eceiza, A.; Corcuera, M. A. Colloids Surf. A: Physicochem. Eng. Asp. 2015, 482, 554.

20. Jiménez-Pardo, I.; Sun, P.; van Benthem, R. A. T. M.; Esteves, A. C. C. Eur. Polym. J. 2018, 101, 324.

21. Hormaiztegui, V.; Mucci, V. L.; Santamaria-echart, A.; Corcuera, M. A.; Eceiza, A.; Aranguren, M. I. J. Appl. Polym. Sci. 2016, 44207, 1.

22. Zhou, C.; Xie, T.; Zhou, R.; Trindle, C. O.; Tikman, Y.; Zhang, X.; Zhang, G. ACS Appl. Mater. Interfaces. 2015, 7, 17209.

23. Liu, K.; Miao, S.; Su, Z.; Sun, L.; Ma, G.; Zhang, S. Eur. J. Lipid Sci. Technol. 2016, 118, 1512.

24. Hormaiztegui, M. E. V.; Aranguren, M. I.; Mucci, V. L. Eur. Polym. J. 2018, 102, 151.

25. Gradinaru, L. M.; Ciobanu, C.; Vlad, S.; Bercea, M.; Popa, M. Ind. Eng. Chem. Res. 2012, 51, 12344.

26. García-Pacios, V.; Jofre-Reche, J. A.; Costa, V.; Colera, M.; Martín-Martínez, J. M. Prog. Org. Coat. 2013, 76, 1484.

27. Wang, J.; Zhang, H.; Miao, Y.; Qiao, L.; Wang, X.; Wang, F. Polymers. 2016, 100, 219.

28. Hsieh, F. Y.; Lin, H. H.; Hsu, S. H. Biomaterials. 2015, $71,48$.

29. Yoo, H. J.; Kim, H. D. J. Biomed. Mater. Res. Part B: Appl. Biomater. 2008, 85, 326.
30. Kim, E. Y.; Lee, J. H.; Lee, D. J.; Lee, Y. H.; Lee, J. H.; Kim, H. D. J. Appl. Polym. Sci. 2013, 129, 1745.

31. Yen, M. S.; Kuo, S. C. J. Appl. Polym. Sci. 1997, 65, 883.

32. Díez-García, I.; Santamaria-Echart, A.; Eceiza, A.; Tercjak, A. React. Funct. Polym. 2018, 131, 1.

33. Fuensanta, M.; Jofre-Reche, J. A.; Rodríguez-Llansola, F.; Costa, V.; Iglesias, J. I.; Martín-Martínez, J. M. Prog. Org. Coat. 2017, 112, 141.

34. Tsai, Y. C.; Li, S.; Hu, S. G.; Chang, W. C.; Jeng, U. S.; Hsu, S. H. ACS Appl. Mater. Interfaces. 2015, 7, 27613.

35. Hsu, S. H.; Chen, C. W.; Hung, K. C.; Tsai, Y. C.; Li, S. Polymers. 2016, 8, E252.

36. Cakić, S. M.; Ristić, I. S.; Krakovský, I.; Stojiljković, D. T.; Bělský, P.; Kollová, L. Mater. Chem. Phys. 2014, 144, 31.

37. Hao, H.; Shao, J.; Deng, Y.; He, S.; Luo, F.; Wu, Y.; Li, J.; Tan, H.; Li, J.; Fu, Q. Biomater. Sci. 2016, 4, 1682.

38. Santamaria-echart, A.; Fernandes, I.; Barreiro, F.; Retegi, A.; Arbelaiz, A.; Corcuera, M. A.; Eceiza, A. Prog. Org. Coat. 2018, 117, 76.

39. Santamaria-Echart, A.; Ugarte, L.; Gonzalez, K.; Martin, L.; Irusta, L.; Gonzalez, A.; Corcuera, M. A.; Eceiza, A. Carbohydr. Polym. 2017, 166, 146.

40. Li, J.; Cui, J.; Yang, J.; Li, Y.; Qiu, H.; Yang, J. Compos. Sci. Technol. 2016, 129, 30.

41. Bezerra, M. R.; Andrade Neto, D.; Galvão, W. S.; Rios, N. S.; de Carvalho, A. C. L. M.; Correa, M. A.; Bohn, F.; Fernandez-Lafuente, R.; Fechine, P. B. A.; de Mattos, M. C.; dos Santos, J. C. S.; Goncalves, L. R. B. Biochem. Eng. J. 2017, 125, 104.

42. Kittelson, D. B. J. Aerosol Sci. 1998, 29, 575.

43. Honakar, H. J. Dispers. Sci. Technol. 2017, 39, 507.

44. Lee, J.; Kim, M.; Hong, C. K.; Shim, S. E. Meas. Sci. Technol. 2007, 18, 3707.

45. Ugarte, L.; Fernandez-d'Arlas, B.; Valea, A.; Gonzalez, M. L.; Corcuera, M. A. Polym. Eng. Sci. 2014, 54, 2282.

46. Król, P.; Król, B. Colloid Polym. Sci. 2012, 290, 879.

47. Pérez-Limiñana, M. A.; Arán-Aís, F.; Torró-Palau, A. M.; Orgilés-Barceló, A. C.; Martín-Martínez, J. M. Int. J. Adhes. Adhes. 2005, 25, 507.

48. Fang, C.; Zhou, X.; Yu, Q.; Liu, S.; Guo, D.; Yu, R.; Hu, J. Prog. Org. Coat. 2014, 77, 61.

49. Cakić, S. M.; Ristić, I. S.; Ristić, O. Z. Polyurethane; InTech: London, 2012. p. 79.

50. Santos, C. C.; Delpech, M. C.; Coutinho, F. M. B. J. Mater. Sci. 2009, 44, 1317.

51. Zhihui, Y.; Guangfeng, W.; Huixuan, Z. J. Appl. Polym. Sci. 2017, 134, 1.

52. Prisacariu, C.; Scortanu, E.; Airinei, A.; Agapie, B.; Iurzhenko, M.; Mamunya, Y. P. Proc. Eng. 2011, 10, 446. 